\title{
PENINGKATAN PENGETAHUAN IBU TENTANG METODE KONTRASEPSI JANGKA PANJANG SEBAGAI UPAYA MENEKAN RISIKO KEHAMILAN
}

\author{
Susanti $^{(1)}$, Sujianti ${ }^{(2)}$ Suko Pranowo ${ }^{(3)}$ \\ STIKES Al-Irsyad Al-Islamiyyah Cilacap
}

Email : santirnj@gmail.com

\section{A. DASAR PEMIKIRAN}

Angka Kematian Ibu (AKI) dan Angka Kematian Bayi (AKB) di Kabupaten Cilacap masih tinggi dan mendapatkan perhatian khusus dari Dinas Kesehatan Kabupaten. Dinas Kesehatan telah melakukan berbagai program untuk menekan AKI dan AKB. Keluarga Berencana sebagai salah satu upaya pemerintah dalam menurunkan AKI.

Angka Kelahiran Total (TFR) Stagnan selama 10 tahun terakhir, hal ini dikarenakan Kepesertaan ber-KB (CPR) hanya meningkat 0,5 persen dalam kurun waktu 5 tahun, masih tingginya angka ASFR 14-19 tahun yaitu $48 / 1.000$ wanita, masih tingginya unmet need (8,5 persen), asih rendahnya peserta KB Metode Kontrasepsi Jangka Panjang /MKJP (10,6 persen). Di Provinsi Jawa tengah prosentase unmetneed tergolong masih tinggi, dan Kabupaten Cilacap berada di rangking kedua yaitu sebesar $15 \%$ dan Contraseption Prevalens Rate (CPR) sebesar 73\%,

hal ini menandakan bahwa masih banyak Pasangan Usia Subur (PUS) tidak menggunakan alat kontrasepsi.

Hasil penelitian di Nigeria menunjukkan bahwa dari 356 responden, ada 98 responden mengalami kehamilan yang tidak diinginkan, dan $76 \%$ dari kehamilan yang tidak diinginkan disebabkan karena tidak menggunakan alat kontrasepsi.(J Bongaarats, 2009). Hasil penelitian meskipun tingkat tahunan diperkirakan penurunan AKI global pada 1990-2008 (2,3\%) jatuh pendek dari tingkat yang diperlukan untuk memenuhi MDG 5 sasaran, itu jauh lebih cepat dari pada yang telah diperkirakan sebelumnya. Upaya ditargetkan untuk meningkatkan akses terhadap kualitas kesehatan ibu, serta upaya untuk mengurangi kehamilan yang tidak diinginkan melalui keluarga berencana, diperlukan untuk mengurangi beban global kematian ibu. (Zureick-Brown S, 2013)

Hasil penelitian tentang Unmet need keluarga berencana di Sudan Timur secara signifikan lebih tinggi di antara perempuan dengan pendidikan yang kurang dan menengah. Juga, hal ini dipengaruhi oleh status pendidikan pasangan dan pekerjaan wanita. Hasil penelitian ini memerlukan kebutuhan untuk manajer program untuk memperhitungkan konsep pendidikan kesehatan reproduksi.(Ali, Abdel A, 2013). Berdasarkan penelitian oleh Susanti (2015) menjelaskan secara analisis uji statistik dari 3 variabel yang dilakukan analisis hanya ada 1 variabel yaitu dukungan keluarga yang mempunyai hubungan dengan kejadian unmetneed dengan nilai $\mathrm{p}<0.005$. 
Sebuah studi cross-sectional dilakukan dengan mewawancarai 2.120 wanita menikah usia 15-49 tahun. Populasi sampel terdaftar di 6 kota besar Iran dengan hasil keseluruhan tingkat prevalensi kontrasepsi adalah $81,5 \%$ dan kebutuhan yang tidak terpenuhi untuk setiap metode kontrasepsi adalah $2,6 \%$ (95\% confidence interval, $2,0 \%-3,3 \%$ ), frekuensi wanita yang menggunakan metode kontrasepsi tradisional (22,3\%), kebutuhan yang belum terpenuhi untuk metode modern diperkirakan sebagai $17,4 \%$. Alasan utama yang diberikan untuk kebutuhan yang belum terpenuhi untuk keluarga berencana yang dianggap risiko rendah kehamilan $(41,8 \%)$ dan oposisi keluarga $(21,8 \%$ dan Kehamilan yang tidak diinginkan dilaporkan oleh $30,7 \%$ dari peserta. Tingkat tinggi kebutuhan yang tidak terpenuhi untuk metode kontrasepsi modern berpotensi menyebabkan peningkatan tingkat kehamilan yang tidak diinginkan dan aborsi.(Motlaq ME, 2013)

Program KB fokus pada kesehatan reproduksi perempuan. Seorang ibu disarankan untuk merencanakan dan mengatur jarak kehamilannya dengan baik. Survei Demografi dan Kesehatan Indonesia (SDKI) 2017 yang dipublikasikan tahun 2018 menunjukkan, prevalensi kelahiran pada usia remaja meskipun turun dibanding lima tahun lalu, tetapi angkanya masih tinggi, yaitu 36 per 1000 kelahiran hidup. "Artinya dari 1000 perempuan yang melahirkan, 36 di antaranya adalah masih di bawah usia 19 tahun. Idealnya untuk kesehatan reproduksi itu di 21 tahun. satu saja kelahiran pada usia remaja seharusnya tidak terjadi. Sebab kelahiran di usia remaja ini meningkatk an risiko bayi lahir stunting dan masalah nasional

pertumbuhan lainnya. Pada ibu pun risiko melahirkan di usia remaja sangat tinggi karena pertumbuhan reproduksinya belum sempurna.

Berdasarkan data di Kabupaten Cilacap sampai bulan Nopember 2018 terdapat kematian ibu sebanyak 1 kematian ibu. Berdasarkan data di Puskesmas Cilacap Tengah pada tahun 2016 dan 2017 masing -masing terdapat 1 kematian ibu, dan terdapat ibu hamil dengan risiko tinggi bedsarkan usia lebih dari 40 tahun. Jumlah ibu hamil sebanyak 823 ibu hamil. Risiko kematian pada ibu hamil dapat terjadi penurunan apabila setelah persalinan menggunakan alat kontrasepsi. Berdasarkan Profil Kesehatan Kabupaten Cilacap (2018) jumlah akseptor baru di Cilacap Tengah I sebanyak 825 orang, dan jumlah akseptore KB aktif sebanyak 6170 jiwa dengan cakupan sasaran program $\mathrm{KB}$ $69 \%$.

Berdasarkan data dari kader $\mathrm{KB}$ Rw 14 Kelurahan Sidanegara jumlah Pasangan Usia Subur (PUS) sebanyak 414 jiwa, dan jumlah akseptor KB sebanyak 333. Akseptor KB IUD sebanyak 75, MOW 16, Implan 13, suntik 71 , pil 28 , kondom 135 , dan MOP tidak ada, sehingga dapat disimpulkan bahwa jumlah akseptor MKJP 104 orang $(31,2 \%)$ dan jumlah akseptor non MKJP sebanyak 234 orang $(70,3)$. Berdasarkan hasil wawancara dengan kader Rw 14 dan bidan desa bahwa disebabkan karena masih seringnya ibu melahirkan sehingga menyebabkan jumlah balita dalam satu keluarga lebih dari dua, sehingga bisa menjadi salah satu faktor risiko pada kehamilan karen usia lebih dari 35 tahun, hal ini diperkuat oleh penelitian Susanti (2019) bahwa paritas berhubungan dengan penggunaan alat kontrasepsi. Berdasarkan data jumlah 
akseptor $68,85 \%$ dari jumlah PUS dan jumlah akseptor KB IUD 2 dari 114 akseptor KB.

\section{B. TUJUAN}

1. Meningkatnya pengetahuan kader posyandu dan ibu-ibu Wanita Usia Subur tentang Metode Kontrasepsi Jangka Panjang (MKJP)

2. Meningkatkan jumlah akseptor $\mathrm{KB}$ MKJP

\section{BENTUK KEGIATAN}

1. Pengabdian masyarakat ini menggunakan penilaian menggunakan kuesioner untuk memperoleh data primer dari responden meliputi pengetahuan dengan menggunakan kuesioner dengan jumlah yang didapatkan adalah 16 orang.

2. Kegiatan pertemuan pertama

a) Pre test tentang MKJP pada ibuibu di Posyandu RT 05 RW 14

b) Pemberian materi MKJP kepada kader Posyandu dan masyarakat

c) Post test tentang MKJP pada ibuibu di Posyandu RT 05 RW 14

d) Konseling dan pendekatan dan deteksi ibu calon akseptor MKJP

e) Identifikasi calon akseptor $\mathrm{KB}$ MKJP oleh kader KB dan kader Posyandu

3. Kegiatan pertemuan kedua

a) Evaluasi pelaksanaan konseling oleh kader Posyandu

b) Pendataan akseptor KB baru

D. SASARAN

Sasaran kegiatan ini adalah kader dan ibu-ibu Wanita Usia Subur di Posyandu RT 05 RW 14 Kelurahan Sidanegara, sebanyak 16 orang

\section{E. TEMPAT DAN WAKTU}

Pengabdian dilaksanakan di Kelurahan Sidanegara Posyandu RT 05 RW 14 Kelurahan
Sidanegara.

Pelaksanaan

pengabdian masyarakat ini

dilaksanakan satu hari pada hari Sabtu 6 Juli 2020 bertempat di $\begin{array}{lllll}\text { Posyandu RT } & 05 & \text { RW } & 14\end{array}$ Kelurahan Sidanegara mulai dari jam 09.00- 11.30 WIB dan tanggal 3 Agustus 2020 jam 09.00

\section{F. PELAKSANA}

Pelaksana kegiatan ini adalah Ketua 1 orang dosen tetap Program Studi S1 Kebidanan, dengan anggota 1 orang dosen tetap Program Studi D3 Kebidanan dan Program Studi S1 Keperawatan. Terdapat pembagian tugas sebagai pelaksana kegiatan yaitu dalam mempersiapkan dan memaparkan materi, serta berkoordinasi dengan pihak Posyandu dalam hal pelaksanan kegiatan juga mendokumentasikan kegiatan yang berlangsung, untuk selanjutnya bersama

\section{G. HASIL KEGIATAN DAN PEMBAHASAN}

Kegiatan penyuluhan dimulai dengan pembukaan, pre test pemateri melakukan penggalian tingkat pengetahuan ibu ibu yang mempunyai balita baik yang sudah menggunakan alat kontrasepsi MKJP dan belum di Posyandu RW 14 tentang bagaimana tingkat pengetahuan ibu ibu yang ada di Posyandu RW 14 terntang alat kontrasepsi MKJP kemudian diberikan materi dan diakhiri dengan post test. Dan perlaksanaan yang kedua untuk mengevaluasi ibu-ibu yang belum menjadi akseptor KB dan yang beralih dari alat kontrasepsi non MKJP menjadi MKJP. 
Keberhasilan kegiatan kooperatifnya peserta mulai dari penyuluhan ini disebabkan

awal pengabdian sampai selesai. Alasan dari aktifnya partisipasi peserta tersebut adalah keingintahuan peserta.

\section{Karakteristik Responden}

Gambaran karakteristik peserta pada pelatihan ini dapat dilihat pada tabel berikut:

Diagram 1. Karakteristik responden

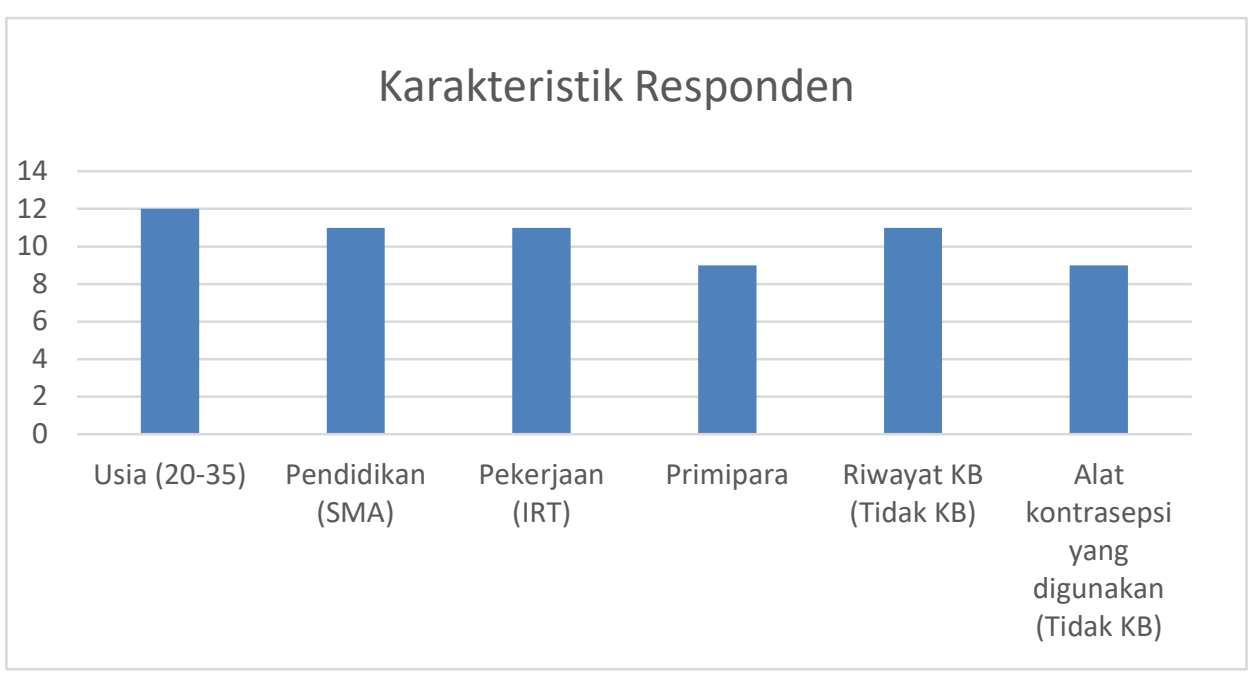

Sumber : data primer tahun 2020

Berdasarkan tabel 1 bahwa usia terbanyak usia 20-35 tahun tahun sebesar 12 orang (75\%), pekerjaan terbanyak adalah tidak bekerja (ibu rumah tangga) sebanyak 11 orang $(68,752 \%)$, pendidikan terbanyak adalah SMA sebanyak 11 orang $(68,75 \%)$, paritas terbanyak paritas 1 sebanyak 9 orang $(56,25 \%)$,), riwayat $\mathrm{KB}$ terbanyak adalah tidak menggunakan $\mathrm{KB}$ sebanyak $\quad 11 \quad$ orang $(68,75 \%)$, dan alat kontrasepsi yang sedang digunakan adalah tidak KB sebanyak 9 orang $(56,25)$

\section{Nilai Pengetahuan Ibu tentang MKJP}

Hasil pre test terhadap 16 WUS didapatkan hasil bahwa nilai terendah adalah 52 dan nilai tertinggi 92 dengan nilai rata-rata 77,5. Sedangkan hasil post test yang dilakukan adalah nilai terendah 76 dan nilai tertinggi adalah 96 dengan nilai rata-rata 86,5.

\section{Tingkat Pengetahuan Ibu} Tentang MKJP

Tingkat pengetahuan WUS pre dan post penyuluhan

di Posyandu RW 14 Kelurahan Sidanegara 


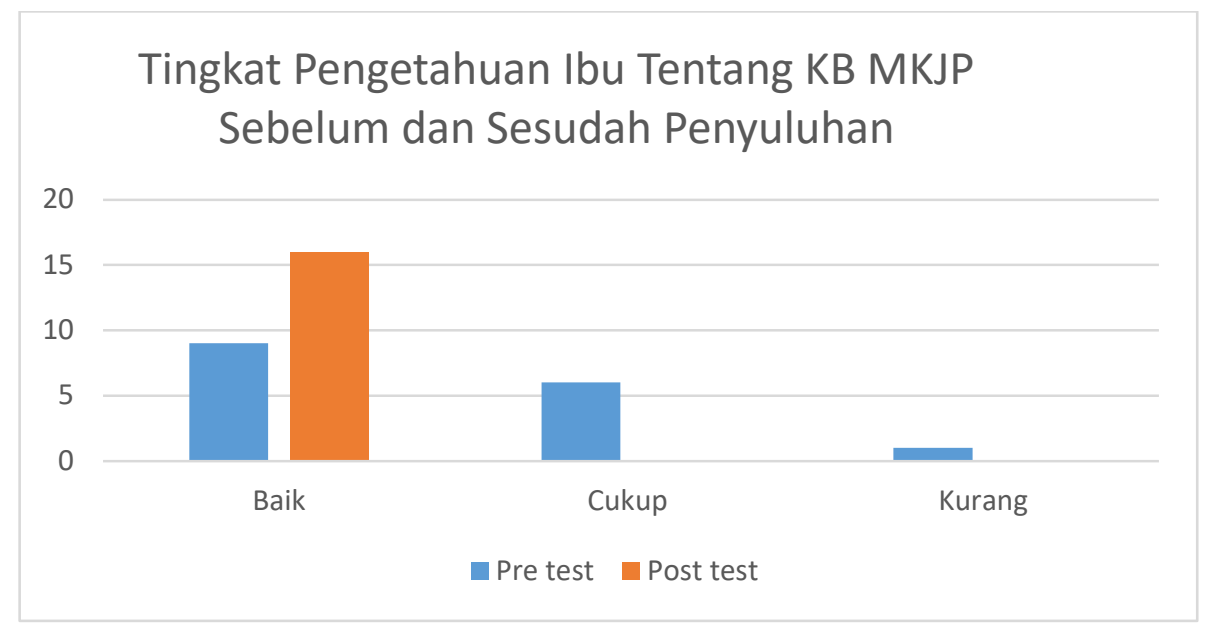

Berdasarkan diagram diatas didapatkan bahwa pengetahuan ibu sebelum penyuluhan adalah 9 orang termasuk kategori pengetahuan baik, 6 orang pengetahuan cukup dan 1 orang pengetahuan kurang, Sedangkan kategori pengetahuan setelah penyuluhan $100 \%$ termasuk dalam kategori pengetahuan baik

Karakteristik repsonden adalah Wanita Usia Subur berjumlah 16 orang. Usia terbanyak pada usia reproduksi sehat 20-35 tahun agama Islam, tingkat pendidikan terbanyak adalah SMA/ sederajat, paritas terbanyak adalah primigravida dan riwayat $\mathrm{KB}$ dan kondisi saat ini terbanyak ibu tidak menggunakan alat kontrasepsi. Hal ini diperkuat oleh penelitian yang dilakukan oleh Susanti (2020) bahwa tingkat pendidikan berhubungan dengan tingkat pengetahuan ibu tentang MKJP dengan nilai $\mathrm{p} 0,033$.

Berdasarkan alat kontrasepsi yang sedang digunakan oleh WUS dapat terlihat bahwa peran serta wanita dalam program Keluarga Berencana tinggi dan peran serta pria masih rendah hal ini dibuktikan dari 16 WUS yang menggunakan alat kontrasepsi suntik 5 orang, IUD sebanyak 1 orang, implant 1 orang, dan MOW 1 orang, kondom 1 orang, dan masih banyak yang belum menggunakan alat kontrasepsi sebanyak 9 orang.

Penyuluhan yang dilakukan adalah penyuluhan tentang alat

kontrasepsi IUD, Implan, Metode Kontrasepsi Mantap/Steriil yang diberikan meliputi pengertian kontrasepsi, macam-macam alat kontrasepsi, indikasi, kontrindikasi, efek samping alat kontrasepsi dan penggunaan alat kontrasepsi. Dan setelah dilakukan penyuluhan tentang alat kontrasepsi beserta kekurangan dan kelebihannya, masyarakat lebih tahu dan dapat mempertimbangkan apakah alat kontrasepsi yang digunakan telah sesuai dengan kebutuhan masing-masing.

Setelah diberikan informasi tentang kontrasepsi, pandangan masyarakat tentang penggunaan alat kontrasepsi terbuka, mereka menjadi tahu bahwa tingkat pengetahuan tentang efek positif dari penggunaan kontrasepsi juga meningkat jadi dapat memilih kontrasepsi yang lebih aman, sehingga pemahaman masyarakat terkait alat kontrasepsi meningkat.

Keluarga berencana dengan programnya merupakan salah satu upaya mengatur kelahiran anak, jarak dan usia ideal melahirkan untuk 
mewujudkan keluarga yang berkualitas. Keluarga berencana memiliki peranan dalam menurunkan risiko kematian ibu melalui pencegahan kehamilan dengan risiko tinggi, menunda kehamilan, membatasi kehamilan maupun mengakahiri kehamilan. Pelayanan keluarga berencana merupakan upaya pelayanan kesehatan preventif yang dasar dan utama (BKKBN, 2011, Sitopu SD, 2012)

Bersarkan hasil pre test terhadap 16 WUS didapatkan hasil bahwa nilai terendah adalah 52 dan nilai tertinggi 92 dengan nilai rata-rata 77,5. Hasil post test yang dilakukan adalah nilai terendah 76 dan nilai tertinggi adalah 96 dengan nilai rata-rata 86,5. Berdasarkan hasil nilai pre test dan post test dapat terlihat adanya kenaikan nilai dari WUS tentang alat kontrasepsi MKJP. Dengan adanya peningkatan tingkat pengetahuan WUS tentang alat kontrasepsi akan menjadi motivasi WUS untuk menggunakan alat kontrasepsi, Akseptor KB didominasi oleh perempuan. Akseptor KB di RT 05 RW 14 Kelurahan Sidanegara yang datang sejumlah 16 orang dan mayoritas 11 orang tidak menggunakan alat kontrasepsi, hal ini kemungkinan karena paritas ibu 1 dengan usia mayoritas pada usia reproduksi sehat antar 20-35 tahun, serta ibu dan keluarga masih merencanakan mempunyai anak. Akseptor $\mathrm{KB}$ dilihat dari pilihan alat kontrasepsi yang banyak digunakan oleh akseptor KB yang masih didominasi oleh alat kontrasepsi yang bersifat hormonal suntik.

\section{H. KESIMPULAN DAN SARAN}

1. Akseptor suntik 5 orang, IUD 1 orang, kondom 1 orang, dan masih terdaapat PUS yang belum
Partisispasi perempuan dalam program Keluarga Berencana yang tinggi ini dapat dilihat dalam dua sisi. Pertama, partrisipasi perempuan dalam program Keluarga Berencana menunjukkan bahwa kesadaran perempuan sudah tinggi. Perempuan sadar akan kesehatan reproduksinya serta mampu untuk membuat perencanaan untuk dirinya maupun keluarganya. Perempuan yang termasuk kepada golongan ini adalah perempuan yang mempunyai tingkat pendidikan yang sudah tinggi.(Nandang, 2017)

Berdasarkan data setelah dilakukan penyuluhan $\mathrm{KB}$ terdapat peningkatan nilai, hal ini menunjukkan bahwa penyuluhan mempunyai efektifitas untuk meningkatkan pengetahuan seseorang, hal ini sesuai dengan hasil penelitian yang dilakukan oleh Lasut (2014) dan Anzani dkk (2013) bahwa terdapat peningkatan pengetahuan yang signifikan pada WUS tentang alat kontrasepsi antara sebelum dan sesudah diberikan penyuluhan dan pendidikan kesehatan, dan juga terdapat hubungan yang signifikan antara tingkat engetahuan dengan pemilihan kontrasepsi dengan nilai p 0,001 menurut (Simanungkalit Happy Marthalena, 2017)

Berdasarkan hasil evaluasi pelaksaan yang kedua pada tanggal 3 Agustus 2020, belum ada penambahan jumlah akseptor KB, karena ibu masih memiliki 1 anak. Untuk ibu yang sudah tidak menginginkan anak lagi sudah mulai memikirkan akan menggunakan alat kontrasepsi MKJP.

menggunakan alat kontrasepsi sebanyak 11 orang.

2. Nilai pengetahuan sebelum penyuluhan rata - rata 77,5 
setelah diberikan penyuluhan meningkat menjadi 86,5 .

Saran

Hendaknya rutin dilakukan penyuluhan dan konseling secara kontinyu sehingga WUS yang datang ke Posyandu meningkat pengetahuannya tetang alat kontrasepsi sehingga dan meningkatkan partisipasi WUS dalam program KB.

\section{DAFTAR PUSTAKA}

Ali Abdel A, A O, 2013;4;13:102. Factors affecting unmet need for family planning in Eastern Sudan. BMC Public Health1.

BKKBN. Kamus istilah kependudukan dan keluarga berencana nasional. Jakarta: Direktorat Teknologi Informasi dan Dokumentasi; 2011.

Dinas Kesehatan Kabupetn Cilacap, 2018, Profil Kesehatan Kabupaten Cilacap $\begin{array}{ll}\text { Bongaarats, SW } & \text { S, } \\ 2013 ; 121(2): 157-61 & \text { A }\end{array}$ response to critics of family planning programs. Int Perspect Sex Reprod Health

Kementrian Kesehatan RI, 2018, Hasil Utama Riskesdas 2018

Motlaq, Mohammad E,Eslami, Mohammad, Yazdanpanah, Mahdieh, Nakhaee, Nouzar, 2013, Contraceptive use and unmet need for family planning in Iran, International Journal Gynaecol Obstet. 2013 May;121(2):157-61. doi: 10.1016/j.ijgo.2012.11.024.
Simanungkalit Happy Marthalena, 2017, Faktor Yang Berhubungan Dengan Pemilihan Alat Kontrasepsi Pada Wanita Di Kota Palangka Raya, Jurnal Kebidanan Vol 3, No 2, April 2017 : 71-76

Sitopu SD. Hubungan akseptor keluarga berencana dengan pengunaan alat kontrasepsi di Puskesmas Helvetia Medan 2012. Jurnal. 2012.

Susanti, Yuni Sapto Edhy Rahayu. 2015. Faktor- Faktor Yang Mempengaruhi Kejadian Unmetneed KB Di Cilacap Tengah Kabupaten Cilacap Tahun 2015. Prosiding UNS. Fakultas Kedokteran D4 Bidan Pendidik UNS

Susanti, Mika Trikumalaswandari. 2019. Factors of using Long-Term Contraception Methods in Reproductive Age Women: Age, Parity, and Husband Support, Jurnal Kebidanan Vol. 9 Nomor 2 92019), hal.168-173

Zilda Oktarina. 2010. Hubungan Berat Lahir dan Faktor Lainnya dengan kejadian Stunting Pada Balita Usia 25-59 bulan di Provinsi Aceh, Sumatera Utara, Sumatera Selatan, dan Lampung Tahun 2010

Zureick-Brown S, Newby $\mathrm{H}$, Chou D, Mizoguchi N, Say L, Suzuki E, et al, 2013;39 (1):3241,Understanding Global Trends in Maternal Mortality. International Perspectives on Sexual and Reproductive Health 

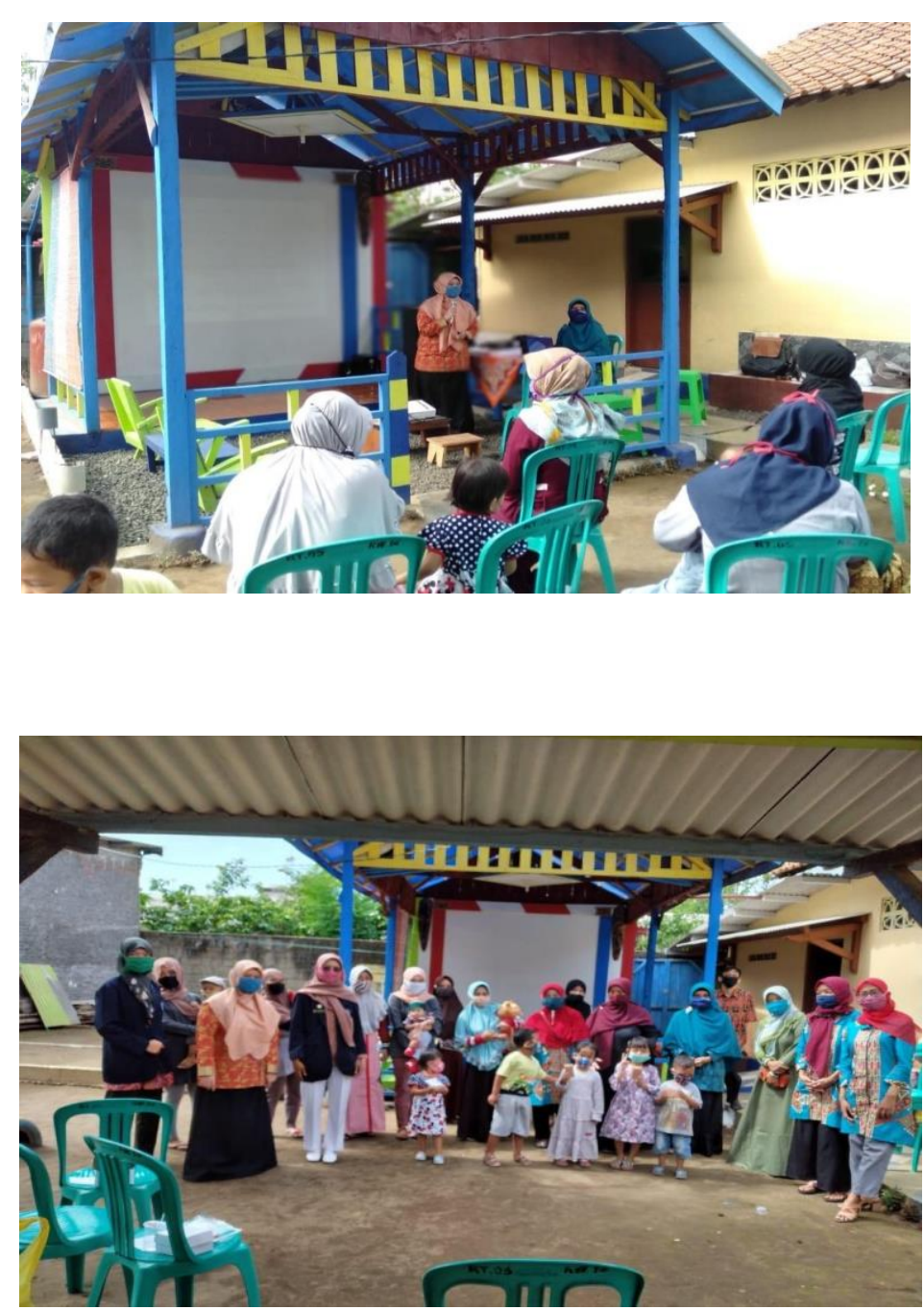